\title{
Interpretation of Early Magnetic Transients Caused by High-Altitude Nuclear Detonations ${ }^{1}$
}

\author{
S. L. Kahalas \\ Mt. Auburn Research Āssociates, Inc., Cambridge, Mass. \\ and \\ P. Newman
}

Air Force Cambridge Research Laboratories, L. G. Hanscom Field, Bedford, Mass.

(Received February 3, 1965; revised February 12, 1965)

\begin{abstract}
A high-altitude nuclear detonation produces magnetic disturbances which propagate to points remote from the detonation area. The worldwide magnetic disturbances occurring within a few seconds after the detonation are discussed. Data from Starfish are presented to show the general characteristics of the early-time magnetic field behavior. Various interpretations of these results are discussed. In particular, there is a signal occurring within a few tenths of a second after the detonation. This is interpreted to be the conventional electromagnetic pulse produced by asymmetric absorption of gamma rays in the lower atmosphere. The pulse propagates to far distances in the earthionosphere cavity. In addition, worldwide data show a second signal occurring within 1.5 to $2 \mathrm{sec}$ after the Starfish detonation. This is also interpreted as an electromagnetic wave propagating in the earthionosphere cavity. It is generated by a bomb-induced magnetohydrodynamic wave which propagates downward from the vicinity of the detonation and is converted to electromagnetic form at the lower boundary of the ionosphere.
\end{abstract}

\section{Introduction}

The high altitude tests of Hardtack [Matsushita, 1959; McNish, 1959; Obayashi, 1963], Argus [Newman, 1959], and Fishbowl [Maeda et al., 1964] have shown that nuclear detonations disturb the geomagnetic field, and that these disturbances are propagated to points remote from the detonation.

From the measurement of geomagnetic disturbances at worldwide stations and from the more or less wellknown properties of a nuclear detonation, it is possible to extract information about properties of the intervening region. This region, between the source of excitation and the measuring station, we shall call the geomagnetic environment. The nuclear detonation acts as a source of excitation of the geomagnetic environment. Measurements of the disturbances at various stations are related to the characteristics of the excitation and of the geomagnetic environment through which the signal propagates. However, from what has been said, it should not be assumed that the bomb serves as a point source of excitation; rather, there are various mechanisms by which a nuclear detonation may excite geomagnetic disturb-

${ }^{1}$ Paper was presented at the ULF Symposium, Boulder, Colo., 17-20 August 1964. ances at great distances from the detonation point, in addition to those which produce local excitation.

In this paper we discuss the mechanisms which have been advanced to explain the signal received at short times (within a few seconds) after a high altitude detonation occurs. The principle source of experimental information that we shall refer to is Starfish of the Fishbowl series, since the time of occurrence (09h oom 09s GMT on 9 July 1962), height of detonation $(400 \mathrm{~km})$, yield (1.4 megatons) and place (over Johnston Island) have been announced [Brown et al., 1963].

We are interested in the geomagnetic signals which occur within times of the order of 1 sec, for several reasons:

(1) It is only recently that broad research effort has been directed toward the study of geomagnetic disturbances with periods smaller than about 1 sec. Consequently much of the data on nuclear detonation-induced perturbations of the geomagnetic field deal with changes of the order of minutes or longer. These longer time data have been reviewed by Maeda et al., [1964] for Starfish. Although a large amount of isolated data have been accumulated for the l-sec magnetic field variations, it has not hitherto been discussed systematically. 
(2) The interaction of the solar wind with the magnetosphere is currently being studied intensively. However, the source of excitation, the solar wind, has properties which are not well known and certainly not well localized in time and space. This introduces difficulties into attempts to deduce short-time magnetospheric behavior from a study of natural geomagnetic storm phenomena. Since the high-altitude nuclear detonation induces short-time (as well as long-time) perturbations in the geomagnetic environment, it does afford a unique opportunity to study the shorttime behavior of the geomagnetic environment [Ward, 1963]. It is particularly important for this study that the time of detonation of the nuclear explosion, in contrast to a geomagnetic storm onset, is known precisely.

In this paper we discuss the geomagnetic perturbations measured at times within a few seconds after detonation for Starfish. In section 2 the observational data are described and classified, together with a description of the requirements imposed by these data on any proposed interpretations. Section 3 contains several interpretations given for the prompt signal and section 4 gives interpretations of the second signal. The last section deals with additional problems introduced in instances where the observed data do not conform with proposed explanations.

TABLE 1. Table of magnetic data (Starfish)

\begin{tabular}{|c|c|c|c|c|}
\hline Station & Observer & $\begin{array}{l}\text { (Amplitude, } \\
\text { time of } \\
\text { arrival) }\end{array}$ & $\begin{array}{c}\text { Approximate } \\
\text { ground } \\
\text { distance }\end{array}$ & $\begin{array}{c}\text { Approximate } \\
\text { bearing }^{b}\end{array}$ \\
\hline Palo Alto, Calif. & Breiner [1963] & $(>20 \gamma, \sim 2 s)$ & $\stackrel{k m}{5,200}$ & $45^{\circ} \mathrm{E}$ \\
\hline Redondo Beach, Calif. & $\begin{array}{l}\text { Crook et al., } \\
{[1963]}\end{array}$ & $\begin{array}{l}(0.3 \gamma, 1 \pm 1 \mathrm{~s}) \\
(7.5 \gamma, 3 \pm 1 \mathrm{~s})\end{array}$ & 5,400 & $50^{\circ} \mathrm{E}$ \\
\hline College, Alaska & $\begin{array}{l}\text { Wilson and } \\
\text { Sugiura [1963] }\end{array}$ & $\begin{array}{l}\text { (Not given, } 2.11 \\
\pm 0.06 \mathrm{~s})\end{array}$ & 5,600 & $5^{\circ} \mathrm{E}$ \\
\hline China Lake, Calif. & $\begin{array}{c}\text { Ashburn et al., } \\
{[1962]}\end{array}$ & $(1.2 \gamma, 1.5 \mathrm{~s})$ & 5,600 & $50^{\circ} \mathrm{E}$ \\
\hline $\begin{array}{l}\text { Victoria, British } \\
\text { Columbia }\end{array}$ & $\begin{array}{l}\text { Caner and } \\
\text { Whitham [1962] }\end{array}$ & $(>18 \gamma, 2.2 \pm 0.1 \mathrm{~s})$ & 5,700 & $30^{\circ} \mathrm{E}$ \\
\hline $\begin{array}{l}\text { Amberley, New } \\
\text { Zealand }\end{array}$ & Gill [1962] & $(\sim 10 \gamma, 4 \pm 2 \mathrm{~s})$ & 6,900 & $180^{\circ}-$ \\
\hline Ottawa, Canada & $\begin{array}{l}\text { Baker and Strome } \\
{[1962]}\end{array}$ & $(1.3 \gamma, 3 \pm 2 \mathrm{~s})$ & 9,100 & $45^{\circ} \mathrm{E}$ \\
\hline Westford, Mass. & $\begin{array}{l}\text { Balser and } \\
\text { Wagner [1963] }\end{array}$ & $\begin{array}{l}\text { (Not given, } \sim 0 \mathrm{~s} \text { ) } \\
\text { (Not given, } \sim 2 \mathrm{~s} \text { ) }\end{array}$ & 9,400 & $50^{\circ} \mathrm{E}$. \\
\hline Scott Base, Antarctica & Gill [1962] & $\begin{array}{c}\text { (Earth Current, } \\
2 \pm 1 \text { s) }\end{array}$ & 10,000 & $180^{\circ}$ \\
\hline $\begin{array}{l}\text { Dumont D'Urville, } \\
\text { Antarctica }\end{array}$ & $\begin{array}{l}\text { Roquet et al., } \\
{[1962,1963]}\end{array}$ & (Not given, $3 \pm 1.5 \mathrm{~s}$ ) & 10,000 & $160^{\circ} \mathrm{W}$ \\
\hline Huancayo, Peru & $\begin{array}{c}\text { Casaverde et al., } \\
{[1963]}\end{array}$ & $\begin{array}{l}(0.3 \gamma / \mathrm{s}, \pm 0.5 \mathrm{~s}) \\
(\sim 12 \gamma, 1.8 \pm 0.1 \mathrm{~s})\end{array}$ & 11,000 & $85^{\circ} \mathrm{E}$ \\
\hline Jicamarca, Peru & $\begin{array}{c}\text { Casaverde et al., } \\
\text { [1963] }\end{array}$ & $\begin{array}{l}(0.2 \gamma, 0 \mathrm{~s}) \\
\text { (large Signal, } \\
1.8 \mathrm{~s})\end{array}$ & 11,000 & $85^{\circ} \mathrm{E}$ \\
\hline $\begin{array}{l}\text { Chambon-la-Foret, } \\
\text { France }\end{array}$ & $\begin{array}{l}\text { Roquet et al., } \\
{[1962,1963]}\end{array}$ & $\begin{array}{l}\text { (Several tenths } \gamma \text {, } \\
-0.2 \pm 0.2 \mathrm{~s} \text { ) } \\
\text { (Several } \gamma, 2 \mathrm{~s} \text { ) }\end{array}$ & 12,600 & $65^{\circ} \mathrm{E}$ \\
\hline Kerguelen Island & $\begin{array}{l}\text { Roquet et al., } \\
{[1962,1963]}\end{array}$ & $\begin{array}{l}\text { (Not given, }-0.3 \\
\pm 0.5 \mathrm{~s} \text { ) }\end{array}$ & 13,500 & $130^{\circ} \mathrm{W}$ \\
\hline
\end{tabular}

${ }^{a}$ Time after burst $(09 \mathrm{~h}$ oom 09s GMT, 9 July 1962).

${ }^{b}$ Relative to Geomagnetic North at Johnston Island.

\section{Observations for Starfish}

Data previously reported in the literature are shown in table 1. It is seen that many of the stations located around the world measure a signal of several gammas or greater at from 1.5 to $2 \mathrm{sec}$ after the detonation time. (This is referred to as the second signal.) At several of these stations, a signal of the order of $1 / 10$ to $1 / 100$ of the amplitude of the second signal is measured within a few tenths of a second after the detonation. (This is referred to as the prompt signal.)

Data taken at various other sites in the Pacific and elsewhere are shown in table 2 . One sees a generally similar behavior to the data of table 1 . The structure of the signal is actually more complex at the near-in stations (e.g., Kaui) and in the conjugate area (e.g., Samoa, Tongatapu) than the data presented in table 2 would indicate. This will be discussed below.

The band-pass characteristic of the equipment used to make the measurements presented in table 2 has been presented by Tepley et al., [1963] for Kaui and Tongatapu. The equipment characteristic for Wake, Samoa, and Trinidad is similar. The equipment has a high-frequency cutoff in the neighborhood of $10 \mathrm{~Hz} .^{2}$ This implies that magnetic signals which are detected by such magnetometers, such as the prompt signal mentioned below, will appear to be practically devoid of frequencies above this. Also, the energy content below $0.1 \mathrm{~Hz}$ is greatly diminished because of the bandpass characteristic of the equipment.

Although it is difficult to classify the data on the basis of amplitude, a few facts emerge:

(1) The prompt signal is measured within tenths of a second at stations all over the earth. Its amplitude is of the order of tenths of gammas with frequencies found to be upwards of $1 \mathrm{~Hz}$.

(2) The second signal appears at stations around the world within 1.5 to $2.2 \mathrm{sec}$ after the detonation. There is no obvious dependence of this time on distance from the detonation. Its amplitude varies widely with station, but generally is greater than 1 gamma. Its frequency is found to be somewhat less than $1 \mathrm{~Hz}$.

TABLE 2. Table of magnetic data from various other sites (Starfish)

\begin{tabular}{|c|c|c|c|}
\hline Station & (Amplitude, time of arrival) ${ }^{a}$ & $\begin{array}{l}\text { Approximate } \\
\text { ground } \\
\text { distance }\end{array}$ & $\begin{array}{l}\text { Approximate } \\
\text { bearing }\end{array}$ \\
\hline Kaui, Hawaii & $\begin{array}{l}\text { (Not given, }<0.1 \mathrm{~s}) \\
(17 \gamma, \sim 1.95 \mathrm{~s})\end{array}$ & $\begin{array}{c}\mathrm{km} \\
1,330\end{array}$ & $55^{\circ} \mathrm{E}$ \\
\hline Wake Island & $\begin{array}{l}\text { (Not given, } 0 \mathrm{~s} \text { ) } \\
(3 \gamma, 1.5 \mathrm{~s})\end{array}$ & 2,600 & $95^{\circ} \mathrm{W}$ \\
\hline American Samoa & $\begin{array}{l}\text { (Earth Current, } 0 \mathrm{~s}) \\
\text { (Earth Current, } 2 \mathrm{~s})\end{array}$ & 3,300 & $175^{\circ} \mathrm{E}$ \\
\hline American Samoa & $(60 \gamma, 1.6 \mathrm{~s})$ & 3,300 & $175^{\circ} \mathrm{E}$ \\
\hline Tongatapu & $\begin{array}{l}\text { (Not given, <0.2 s) } \\
(27 \gamma, 1.7 \mathrm{~s})\end{array}$ & 4,200 & $180^{\circ}$ \\
\hline Trinidad & $\begin{array}{l}\text { (Not given, } 0 \mathrm{~s}) \\
(\sim 5 \gamma, 1.9 \mathrm{~s})\end{array}$ & 11,600 & $95^{\circ} \mathrm{E}$ \\
\hline Trinidad & $\begin{array}{l}\text { (Earth Current, } 0 \mathrm{~s} \text { ) } \\
\text { (Earth Current, } 1.5 \mathrm{~s} \text { ) }\end{array}$ & 11,600 & $95^{\circ} \mathrm{E}$ \\
\hline
\end{tabular}

a Time after burst (09h oom 09s GMT, 9 July 1962).

${ }^{b}$ Relative to Geomagnetic North at Johnston Island.

\section{Interpretation of the Prompt Signal}

It is well known that a nuclear detonation at high altitude generates an electromagnetic pulse [Glass-

\footnotetext{
${ }^{2} 1 \mathrm{~Hz}$ equals 1 cycle per second.
} 
tone, 1962; Kompaneets, 1958; Karzas and Latter, 1962] in the region of the atmosphere where gammaray absorption occurs $(20$ to $50 \mathrm{~km})$. While the pulse may have frequencies as high as $100 \mathrm{MHz}$, most of the energy is contained at lower frequencies, around tens of kilohertz. This pulse will propagate in the earth-ionosphere cavity at close to the velocity of light, with the lower frequencies being attenuated less. Thus the pulse may be expected to appear at any station in a time less than about $1 / 8$ sec.

Besides the electromagnetic pulse, there are several other possible mechanisms which can generate a magnetic disturbance at large distances from the detonation within a few tenths of a second.

\subsection{Neutron Decay Beta Effects}

Neutrons are emitted by the bomb in all directions. These travel very quickly to far distances and decay into a proton and an electron. The electron in turn will spiral along the geomagnetic field line and produce a magnetic disturbance either by Cerenkov radiation [Davis and Headrick, 1964] or by creating enhanced ionization in the $D$ and $E$ regions [Crain and Tamarkin, 1961; Field, 1963] (enhanced $S_{q}$ effect). It is also possible for the neutron decay protons to produce a similar effect, although it takes them longer to arrive at a given station than the electrons. The difficulty with this mechanism is that the magnetic field line through a station such as Chambon-la-Foret in France, which recorded the prompt pulse, is not accessible to line-of-sight neutrons. Furthermore, the multiple scattering that the neutrons would have to suffer in reaching the proper magnetic field lines would decrease the magnitude of the neutron (and hence the beta) flux by many orders of magnitude over the value for line-of-sight stations.

\subsection{Whistlers}

Whistlers were produced by Starfish [Allcock et al., 1963]. Basically, these waves are guided by the geomagnetic field, so that their effects would be expected to be confined to the conjugate regions.

We conclude that the only mechanism which can account for a magnetic disturbance at stations all over the world within a few tenths of a second after detonation is the electromagnetic pulse (generated below the ionosphere) which propagates in the earth-ionosphere cavity at light speed.

\section{Interpretation of the Second Signal}

There have been several different mechanisms proposed to explain the second signal. These are discussed and criticized.

\subsection{Magnetohydrodynamic Wave Propagation}

One proposed explanation is that the early-time disturbances are magnetohydrodynamic waves initiated in the detonation region by the displacement of the geomagnetic field by the highly conductive fireball [Glasstone, 1962; Leipunskii, 1960]. The magnetohydrodynamic waves then propagate in the upper ionosphere (above $1000 \mathrm{~km}$ ) to the vicinity of the observation point in ducts, as was proposed by Bomke et al., [1960] in connection with Argus. According to these authors and to Berthold et al., [1960] (who analyzed the amplitude dependence of the signals from Argus III), it is possible to account for the early. time signal in Argus III (corresponding to the second signal in Starfish) as being the ordinary magnetohydrodynamic (fast magnetoacoustic) mode. Another Argus III signal, arriving later, within tens of seconds after detonation, is attributed to propagation of the extraordinary (pure Alfvén) mode.

This concept suffers from several difficulties. One point is that the time for propagation of the magnetohydrodynamic wave from its altitude above $1000 \mathrm{~km}$ to the observing station was not included by Bomke et al., [1960] in computing arrival times. With this correction, magnetohydrodynamic wave arrival times become considerably too long. A second point is that the wave must propagate at velocities greater than minimum in order to account for the short time delay of the early-time Argus III signal or the second signal of Starfish. However, refraction would tend to keep the ordinary mode propagating in the duct near $400 \mathrm{~km}$ altitude where the Alfvén velocity is a minimum. The extraordinary mode, which is guided by the geomagnetic field lines, would propagate at higher altitudes and therefore higher velocities. However, this wave would appear to be limited to producing disturbances in the conjugate region.

A modification of this theory which increases the velocity of magnetohydrodynamic wave propagation in the ionosphere has been proposed [Caner and Whitham, 1962]. The modification is that the magnetohydrodynamic wave is a shock wave which propagates at several times the Alfvén velocity. While this concept is quite likely correct close in to the detonation, it can be shown theoretically that the shock wave would be expected to decay into a small amplitude wave over the distances of propagation involved. Furthermore, the amplitude of the second signal measured at many stations is of the order of tens of gammas for Starfish. Allowing for the possibility of attenuation through the $E$ region, the amplitude above this region might be about 1000 gammas which is a factor of 50 less the ambient field amplitude. This would imply that the disturbance, if it propagates magnetohydrodynamically, is a small amplitude wave at most stations listed above.

\subsection{Neutron Decay Beta Effects}

The mechanism of ionization produced by neutron decay beta rays may be invoked to explain the second signal of Starfish. However, since stations whose magnetic field lines are not accessible to line-of-sight neutrons received the second signal, this concept does not appear to offer an acceptable explanation. 


\subsection{Magnetohydrodynamic Excitation of the Earth- Ionosphere Cavity}

It was recognized from the Argus tests [Newman, 1959] that the early-time signal (occurring within 4 sec after detonation) of Argus III might not be accessible to explanation as propagation by purely magnetohydrodynamic means. A different model was therefore developed [Kahalas, 1960] which has also been discussed by other authors [Caner and Whitham, 1962; Roquet et al., 1963] on the basis of Starfish data. In this model, the fireball of a nuclear detonation creates magnetohydrodynamic waves as before. Some of this wave energy propagates downward (at magnetohydrodynamic speeds) and is converted into electromagnetic waves in the lower ionosphere. This electromagnetic wave then propagates in the earthionosphere cavity around the earth at close to light speed. The time delay in the observed signal, in this model, comes mainly from the time it takes a magnetohydrodynamic wave to propagate from the detonation point to the lower ionosphere.

For Starfish, occurring at $400 \mathrm{~km}$ height, the calculation of the propagation time from 550 to $80 \mathrm{~km}$ by Francis and Karplus [1960] may be used. For the ordinary wave the time is 1.4 sec. Although this time is computed for a daytime ionosphere and Starfish occurred at night, it may be expected that the bomb's radiations would perturb conditions to approximate a daytime state. For Argus III, which took place at a height above the Starfish altitude, the observed time delay would be expected to be somewhat greater than for Starfish. However, Starfish increased the ionization in the lower ionosphere, so that the Alfvén velocity may have been sufficiently diminished to offset the higher altitude of Argus III.

Thus, the concept of magnetohydrodynamic wave excitation of the earth-ionosphere cavity would explain how a signal could occur at widely separated stations around the earth at approximately the same time.

There are problems associated with this explanation. For Starfish there is an apparent spread in arrival times from 1.5 to $2.2 \mathrm{sec}$. The time delay, however, does not increase in a systematic way for stations further from the detonation. A possible explanation may be that the spread of onset times for different stations is caused by difficulties in reading the record for the exact instant of onset. However, if the mechanism of magnetohydrodynamic excitation of electromagnetic waves in the earth-ionosphere cavity is valid, then a new mechanism for the onset of natural geomagnetic storms seems to be indicated.

\section{Anomalous Near-in and Conjugate Region Effects}

The presentation of the data given above is substantially correct, but there are deviations from the simple picture at near-in and conjugate region stations. This would imply that the physical processes occurring

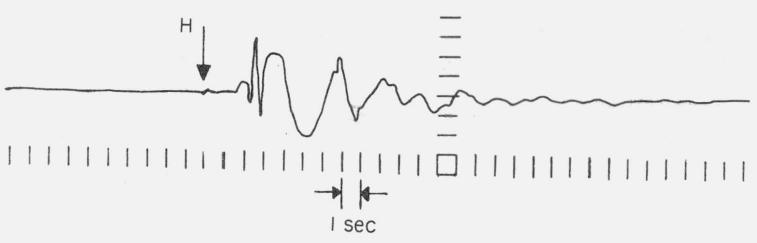

Figure 1. E-W magnetometer Wake Starfish.

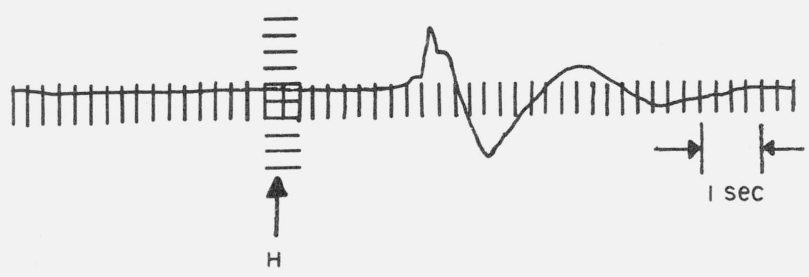

Figure 2. E-W magnetometer Samoa Starfish.

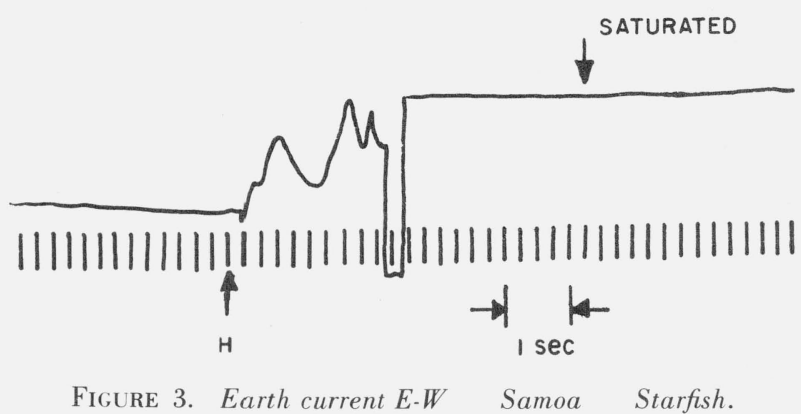

are more complicated than the theoretical interpretation presented above might indicate. In particular, one might expect that close enough in to the region of detonation, anomalous signals might be observed which have not been attenuated by propagation to large distances over the earth's surface. In the same vein, the guiding effect of the geomagnetic field on both waves and charged particles should lead to special effects in the conjugate regions.

There are several anomalies which have been noticed in the data. Figure 1 shows the magnetic disturbance at Wake Island, $2600 \mathrm{~km}$ away. It is seen that there are two onsets, one at about $1.5 \mathrm{sec}$ and another at slightly greater than 2 sec. Figure 2 shows the magnetic record at Samoa, $3300 \mathrm{~km}$ away. Again the same phenomenon of two apparent onsets appear. 
Another anomaly involves the observation at Wellington, New Zealand, of a magnetic signal appearing at $0.6 \pm 0.2 \mathrm{sec}$ after the detonation [Christoffel, 1962]. This correlates very closely with the observed time of arrival of a whistler at the same site [Allcock et al., 1962]. It is suggested that the magnetic disturbance measured at Wellington may have been associated with the whistler. Figure 3 shows the earth-current record at Samoa in the conjugate region. There is apparently an onset in the vicinity of 0.5 sec, which suggests again a whistler arrival at this site.

Such anomalous effects indicate that a great deal is yet to be learned about magnetic disturbances from nuclear detonations and their relationship to extremely low-frequency wave propagation in the terrestrial atmosphere.

The data included herein were taken by Nuclear Research Associates, Inc., and Lockheed Corporation under an Air Force Cambridge Research Laboratories project. S. L. Kahalas acknowledges the contribution made by H. E. Stubbs. This work was supported by the Defense Atomic Support Agency and the Air Force Cambridge Research Laboratories.

\section{References}

Allcock, G. McK., R. A. Helliwell, C. K. Branigan, and J. C. Mountjoy (1962), Whistler and other VLF phenomena, New Zealand J. Geol. Geophys. 5, 975-977.

Allcock, G. McK., C. K. Branigan, J. C. Mountjoy, and R. A. Helliwell (1963), Whistler and other very low frequency phenomena associated with the high-altitude nuclear explosion of July 9, 1962, J. Geophys. Res. 68, 735-739.

Ashburn, E. V., J. P. Lee, and R. N. Francis (1962), Observations of the changes in the earth's magnetic field induced by the highaltitude nuclear explosion of July 9, 1962, J. Geophys. Res. 67, 4933-4934.

Baker, R. C., and W. M. Strome (1962), Magnetic disturbance from a high-altitude nuclear explosion, J. Geophys. Res. 67, 4927-4928.

Balser, M., and C. A. Wagner (1963), Effect of a high-altitude nuclear detonation on the earth-ionosphere cavity, J. Geophys. Res. 68, 4115-4118.

Berthold, W. K., A. K. Harris, and H. J. Hope (1960), World-wide effects of hydromagnetic waves due to Argus, J. Geophys. Res. 65, $2233-2239$

Bomke, H. A., W. J. Ramm, S. Goldblatt, and V. Klemas (1960), Global hydromagnetic wave ducts in the exosphere, Nature 185, 299-300.

Breiner, S. (1963), Effect of nuclear detonation on the geomagnetic field at Palo Alto, California, J. Geophys. Res. 68, 335-337.

Brown, W. L., W. N. Hess, and J. A. Van Allen (1963), Introduction to collected papers on the artificial radiation belt from the July 9 , 1962, nuclear detonation, J. Geophys. Res. 68, 605-606.

Caner, B., and K. Whitham (1962), A geomagnetic observation of a high-altitude nuclear detonation, Can. J. Phys. 40, 1846-1851.

Casaverde, M., A. Giesecke, and R. Cohen (1963), Effects of the nuclear explosion over Johnston Island observed in Peru on July 9, 1962, J. Geophys. Res. 68, 2603-2611.
Christoffel, D. A. (1962), Onset time at Wellington of geomagnetic micropulsations from the Johnston Island high-altitude nuclear explosion of 9 July 1962, New Zealand J. Geol. Geophys. 5, 960963.

Crain, C. M. and P. Tamarkin (1961), A note on the cause of sudden ionization anomalies in regions remote from high-altitude nuclear bursts, J. Geophys. Res. 66, 35-39.

Crook, G. M., E. W. Greenstadt, and G. T. Inouye (1963), Distant electromagnetic observations of the high-altitude nuclear detonation of July 9, 1962, J. Geophys. Res. 68, 1781-1784.

Davis, J. R., and J. M. Headrick (1964), A comparison of high altitude nuclear explosion effects in the $E$ layer with variations in geomagnetic field strength, J. Geophys. Res. 69, 911-916.

Field, E. C. (1963), On geomagnetic fluctuations in regions remote from high-altitude nuclear bursts, J. Geophys. Res. 68, 1172-1173.

Francis, W. E., and R. Karplus (1960), Hydromannetic waves in the ionosphere, J. Geophys. Res. 65, 3593-3600.

Gill, P. J. (1962), Magnetic and earth-current effects of the highaltitude nuclear explosion on 9 July 1962, New Zealand J. Geol. Geophys. 5, 943-953.

Glasstone, S. (Ed.) (1962), The effects of nuclear weapons (rev. ed., Defense Atomic Support Agency, U.S. Govt. Printing Office, Washington, D.C.).

Kahalas, S. L. (1960), Magnetohydrodynamic wave propagation in the ionosphere, Phys. Fluids 3, 372-378.

Karzas, N. J., and R. Latter (1962), The electromagnetic signal due to the interaction of nuclear explosions with the earth's magnetic field, J. Geophys. Res. 67, 4635-4640.

Kompaneets, A. S. (1958), Radio emission from an atomic explosion, Soviet Phys. JETP (English Transl.) 35, 1076-1080.

Leipunskii, O. I. (1960), Possible magnetic effects from high-altitude explosions of atomic bombs, Soviet Phys. JETP (English Transl.) $11,219-221$.

Maeda, H., A. J. Shirgaokar, M. Yasuhara, and S. Matsushita (1964), On the geomagnetic effect of the Starfish high-altitude nuclear explosion, J. Geophys. Res. 69, 917-945.

Matsushita, S. (1959), On artificial geomagnetic and ionospheric storms associated with high-altitude explosions, J. Geophys. Res. 64, 1149-1161.

McNish, A. G. (1959), Geomagnetic effects of high-altitude nuclear explosions, J. Geophys. Res. 64, 2253-2265.

Newman, P. (1959), Observations of high-altitude nuclear detonations, J. Geophys. Res. 64, 923-931.

Obayashi, T. (1963), Upper atmospheric disturbances due to highaltitude nuclear explosions, Planetary Space Sci. 10, 47-63.

Roquet, J., R. Schlich, and E. Seltzer (1962), Magnétisme terrestre.Perturbations transitoires mondiales du champ magnétique terrestre, observées en France lors de l'explosion nucléaire spaciale du 9 juillet 1962, Compt. Rend. 255, 549-551.

Roquet, J., R. Schlich, and E. Seltzer (1963), Evidence of two distinct synchronous world impulses for the magnetic effects of the nuclear high-altitude detonation of July 9, 1962, J. Geophys. Res. 68 , 3731-3732.

Tepley, L., R. C. Wentworth, K. G. Lambert, H. V. Prentiss, K. D. Amundsen, and D. R. Hillendahl (1963), Sub ELF geomagnetic fluctuations, Vol. III, Lockheed Missiles and Space Co. Report 8-08-64-1, AFCRL-64-204 (III).

Ward, S. (1963), Dynamics of the magnetosphere, J. Geophys. Res. 68, 781-788.

Wilson, C. R., and M. Sugiura (1963), Hydromagnetic waves generated by the July 9,1962 , nuclear weapons test as observed at College, Alaska, J. Geophys. Res. 68, 3149-3153.

(Paper 69D8-549) 